\title{
Public perception of social work and social workers in Aotearoa New Zealand
}

\author{
B. Staniforth, C. Fouché and L. Beddoe
}

The authors are all members of the School of Counselling, Human Services and Social Work at The University of Auckland, Auckland, New Zealand.

\section{Abstract}

There have been limited studies that have looked at how the public perceive social workers and the profession of social work. This study reports results of a telephone survey in which 386 members of the public in Aotearoa New Zealand were asked about their beliefs and impressions about social work and social workers. Study findings demonstrate that members of the public surveyed appeared relatively well informed about what social workers do, and were generally positive in their views.

\section{Introduction}

Social work in New Zealand has undergone significant and rapid change over the 50 years since its professional body, the Aotearoa New Zealand Association of Social Workers (ANZASW), was founded. ${ }^{1}$ In that time, no large-scale studies have explored how people view social workers or the profession of social work in Aotearoa New Zealand. It is our contention that there are several reasons why this issue is an important one to explore, including but not limited to public confidence in the profession, incentives for people to enter the profession, filling social work vacancies and funding of services.

This paper will briefly review some of the literature related to previous studies on perceptions of social work in order to establish themes and to situate this research. Findings of a recent study of members of the public in Aotearoa New Zealand will then be presented, with discussion following on the implications of these results for the profession of social work and social workers.

\section{Literature review}

A review of the literature revealed that there have been limited studies undertaken which explore how social workers and the profession of social work have been perceived. In this review the Aotearoa New Zealand research will be described specifically first, with themes emerging from the international literature following.

ANZASW was initially founded in 1964 as The New Zealand Association of Social Workers (NZASW) and changed its name to ANZASW in 1998. 
There have been two small studies conducted in Aotearoa New Zealand. The first was a small research project conducted by Turner (2011) as part of a Master of Social Work Applied degree, where a small self-selected sample of people $(\mathrm{N}=30)$ responded to an online survey. In this project, Turner found that most people were able to explain what social workers did, there was some recognition that social workers were needed and that social work was a difficult job. There was some belief expressed that social workers were 'do-gooders' and that they 'helped people'. One quotation summarises the characteristics of the flavour of social work particularly in Aotearoa New Zealand:

I picture your average social worker as a middle-aged, grey haired woman in bright coloured but comfortable clothes, wearing a Māori pendant and comfortable shoes. She's a tough nut with a good (if slightly black) sense of humour and is a very caring person. (Respondent 6, cited in Turner, 2011, p. 28).

The other local study was conducted by the Social Workers Registration Board in 2011, as part of its review of the Social Workers Registration Act 2003. One of the questions asked in the survey was, 'If you were referring a friend or relative to see a professional for help with a personal problem, how much confidence would you have in each of the following professionals to assist them?' This study had a margin of error of $+/-4.7 \%$ and found that only $12 \%$ of the sample felt that they would have a 'great deal of confidence' in social workers, compared to therapists $(10 \%)$, counsellors (16\%), psychologists $(24 \%)$ and psychotherapists $(18 \%)$. At the other end of the scale, in response to 'no confidence at all' $8 \%$ of the sample stated that this was the case for social workers, with therapists (11\%), counsellors also at $8 \%$, psychologists $(9 \%)$ and psychotherapists (12\%) (SWRB, 2012).

A review of the international literature revealed several themes. These relate to the themes of perceptions of social workers' roles and areas of practice; registration and educational requirements; links to gender; and the role that the media plays.

\section{Role clarity, tasks and areas of practice}

Several studies have revealed that there is some confusion about the roles of social workers and the settings they work within (Davidson \& King, 2005; Condie, Hanson, Lang, Moss \& Kane, 1978). Davidson and King's study for the Scottish Executive found that while there was good general knowledge about what social workers did, 'detailed knowledge about social workers and specifically about the different services they provide and the means by which these can be accessed, was fairly low among significant proportions of research participants' (Davidson \& King , 2005, p. 7).

Many of the studies have indicated that there is a perception that social workers are principally involved in child protection, and that, other than this association, there is confusion about what we do (Hackett, Kuronen, Matthies, \& Kresal, 2003; LeCroy \& Stinson, 2004; Davidson \& King, 2005; Krumer-Nevo \& Weiss, 2006; Schmid \& Benbenishty, 2011; Condie, Hanson, Lang, Moss, \& Kane, 1978). This confusion is also reflected in research which has considered how other professions who work alongside social workers, such as physicians and nurses, have perceived the roles of social workers (Netting \& Williams, 1996; Black, 2006; Keefe, Geron, \& Enguidanos, 2009; Egan \& Kadushin, 1995; Postle, 2001).

This confusion and lack of clarity about what social workers do is arguably reflected in a study where only $15.7 \%$ of social work student respondents had a good understanding 
of social work practice (Dennison, Poole \& Qaquish, 2007). In another study of social work, psychology and students from other majors, there was a lack of understanding about social work roles and functions. More importantly, social work students themselves did not have a good understanding about their chosen profession, as noted in a study conducted by Jones, Vela, Vang and Walde (2006).

Some studies have found that the profession's public image may reflect the profession's own confusion about what we do (Davidson \& King, 2005; Keefe, Geron \& Enguidanos, 2009). Given that the profession is largely constructed within specific contexts, this is not all that surprising (Payne, 2005). Social work's broad scope makes it hard to demarcate its boundaries and roles, especially in regards to whether social workers should 'be helping people change themselves, or be involved in changing society' (Staniforth, Fouché \& O’Brien, 2011, p. 193).

\section{Perceptions on registration and educational requirements}

The New Zealand SWRB (2011) study found that $81 \%$ of the participants surveyed believed that registration was required for social workers and $80 \%$ believed that social work required a minimum qualification for practice (SWRB, 2012). LeCroy and Stinson (2004), and Davidson and King (2005) reported on awareness of qualifications required for social work practice. Davidson and King (2005) asked respondents to choose from a list of possible qualifications: 'Just over two in five (44\%) correctly chose 'three or four years' training, equivalent to a university degree' (p. 34). A further $25 \%$ believed that social workers had taken 'two or three years' training, equivalent to a college diploma'. A small minority thought that social workers are required to undertake only a year's training and practical experience' (p. 35).

\section{Gender}

Several studies have found that there is a strong perception that social work is a gendered profession, dominated by women (Research Works, 2001; LeCroy \& Stinson, 2004; Davidson \& King, 2005; Gerritsen-McKane, Hunter, \& Ofori-Dua, 2013). Pease (2011) mentions various surveys where the findings report on gender: women make up 79\% of the membership of the National Association of Social Workers in the United States (citing Sakamoto, McPhail, Anastas, \& Colarossi, 2008); 87\% of the workforce in England (citing the General Social Care Council (2010) and 83\% of all professional social workers in Australia (citing Healy \& Lonne, 2010). This link to gender has also been hypothesised as one of the reasons why there may be low status and pay within the profession, as it has predominantly been associated with being a female profession. McPhail (2004) offers some challenges to simple explanations for this factual numerical domination, arguing that while typically heroic accounts of the female founders of social work flourish in the professional discourse, these mask institutional sexism and often invisible barriers to women's leadership. It is possible though that from the outside, men may perceive less opportunity for them in social work, an aspect worthy of further study.

\section{Media representation}

There is a belief purported in many studies that the media influences public perception of the profession and of social workers (NASW, 2003; Briggs, Meagher \& Healy, 2007; Brodie, Nottingham \& Plunkett, 2008; Jones, Vela, Vang, \& Walde, 2006; Zugazaga, Surette, Mendez, \& Otto, 2008; Davidson \& King, 2005; Turner, 2011). In summarising comments by focus group members in the Davidson and King study it was noted that: 
In all groups there was spontaneous reference to the 'bad press' that social workers receive, with participants generally feeling that this is perhaps unfair and a reflection of a broader tendency on the part of the media to highlight bad rather than good news (2005, p. 25).

Media presentation of social work has not been well explored in Aotearoa New Zealand, but negative aspects of media framing have been noted by several authors. Stanfield and Beddoe (2013) note that the New Zealand social work experience is similar to that in the United Kingdom, albeit with less focus on individual public scapegoating. Brown (2000) noted an impact on social work retention in Child Youth and Family of 'the cumulative, caustic effects of negative media portrayal and poor public perception' (p. 51). The need to address such perceptions with positive strategies had been noted earlier by Lytollis (1996) and Beddoe (2003) who reported students being distressed by what they perceived as unfair and stereotypical characterisations of the profession. Van Heugten (2011) discusses the stress experienced by social workers in Aotearoa New Zealand, making particular reference to the poor image of social workers in this country, and the excessive criticism directed at the profession both politically and publicly. Elsewhere there is significant discussion of media representation of the profession (see, for example: Henderson \& Franklin, 2007; Freeman \& Valentine, 2004; Gaughan \& Garrett, 2011).

As part of this research project, an analysis of a sample of newspaper coverage of social work and social workers was undertaken, and the authors hope to have the results of this published in another paper at a later date.

\section{Methodology}

A literature review was conducted from November 2012 to February 2013 and was funded through The University of Auckland's Summer Scholar programme. From here a questionnaire $^{2}$ was developed and ethical consent for the project was granted by the University's Human Participants Ethics Committee.

The researchers commissioned a private research company to undertake the research, using a phone survey design. In this design, numbers were randomly allocated to a national calling sample. Data collection was undertaken using a six-time call-back protocol. In this process, each number was called back up to six times at different times of the day, and days of the week, to ensure an opportunity was provided for participation in the research. Only after potential respondents declined to take part, or were not been able to be contacted after six attempts, were the numbers discarded and new numbers included in the sample.

The phone survey was conducted from October 5-10th, 2013. There were 386 questionnaires completed nationally. Data was collected on a quota-based system to reflect the national population. The response rate was $30 \%$. This sample provided data with a maximum margin of error of $+/-5 \%$.

There were 17 questions in the questionnaire, with a mixture of statements using a Likert response, closed and open questions. Closed and Likert question responses were analysed

A copy of the questionnaire can be obtained through emailing the principal author on b.staniforth@auckland. ac.nz. 
through SPSS with cross tabulation done using Chi Square and Cramer's V tests for significance. Responses to open questions were analysed thematically. For cross tabulation, ethnicity was grouped into 'European' (79.3\%) and 'All other groups' (20.7\%).

\section{Respondent characteristics}

Demographic questions were asked in regards to gender, age, ethnicity, residence (location and geography) and if the respondent or anyone in their family had used social work services previously.

Within the sample, $45.7 \%$ of respondents reported to be male, $54.3 \%$ female, and none as transgendered. This compares to 2013 NZ Census data that shows the country's population being made up of $48.7 \%$ men and 51.3\% women (Statistics New Zealand, 2014).

In terms of age, there was a good distribution of age from respondents 18 and over to over 65. There was a slight over representation of people 65 years and above, with 2013 Census data revealing this group to comprise $14.3 \%$ of the total population as compared to $18.4 \%$ in this study (Statistics New Zealand, 2014).

New Zealand European/Pakeha were slightly over-represented in this study $(79.5 \%)$ compared to 2013 Census data $(74 \%)$ with other groups being underrepresented. Māori comprised $14.9 \%$ of population compared to $5.8 \%$ of the study sample. Pacific Peoples comprised $7.4 \%$ of population compared to $2.3 \%$ of study sample, and Asian people made up $11.8 \%$ of the general population in 2013 , compared to $4.3 \%$ of the study sample (Statistics New Zealand, 2014).

There were a large number $(42.9 \%)$ of respondents from Auckland, with similar numbers reporting coming from Christchurch $(12.6 \%)$, Wellington $(13.1 \%)$, and other South Island, other North Island (14.4\%) regions.

Of the respondents in the study, $42.7 \%$ indicated that they or a close family member had used social work services, while $54.5 \%$ indicated that they had not. Of those responding, $2.8 \%$ did not know, or did not answer the question.

\section{Results and discussion}

The results and discussion in this section are grouped thematically, partly reflecting the themes that emerged from the literature review. These include perceptions on the role of social work; working conditions, including issues of retention and recruitment; and aspects related to registration and education. While the literature review revealed issues to do with gender and media representation of the study, these are not represented to a large degree in this study.

\section{Perceptions of the social work role}

There were two open-ended questions posed to respondents. The first question asked participants to state the first sentence that came to mind when they heard the word 'social worker'. Most responses were linked to social work role or tasks while some were more descriptive of the person or profession. Table one demonstrates the variety of responses to this question. The most common response was 'helper' with $45 \%$ of respondents $(n=165)$ 
providing an answer along these lines. The next most common response, from $34 \%(\mathrm{n}=42)$ of respondents was 'meets specific personal needs'. Children/youth help was mentioned by 34 respondents, with the same number stating 'meets specific community needs' and again the same number linking social work with statutory organisations such as Children Youth and their Families Service, Work and Income New Zealand or 'government'. 'Counsellor or someone who listens' was mentioned by $22 \%$ of respondents. Other themes that emerged were: caring (13\%), works for love/ charity (11\%), 'do-gooder' (9\%), visiting people in need $(7 \%)$, advocacy (4), woman (4). Within the 'other' category, there were several responses that were more derogatory. These included: An ex-school teacher that can't get a job; not that complimentary; don't have a good name in the field; interfering; namby-pamby; hopeless; wimp; down at heel; bad; annoying. A similar question was asked in the Davidson and King (2005) study with reported results appearing to be very consistent to this study.

Table one. First sentence that comes to mind when you hear 'social worker'.

\begin{tabular}{lc} 
Response & $\begin{array}{c}\text { Number of } \\
\text { respondents }\end{array}$ \\
Helper & 165 \\
Meets specific personal needs & 42 \\
Children/youth help & 34 \\
Meets specific community needs & 34 \\
CYFS/WINZ/government & 34 \\
Counsellor/ someone who listens & 22 \\
Caring & 13 \\
Works for love of it/charitable & 11 \\
'Do gooder' or good person & 9 \\
Visiting people in need & 7 \\
Advocacy & 4 \\
Woman or female profession & 4 \\
Necessary part of society & 3 \\
Broad range of roles & 1 \\
Don't know or none & 18 \\
Other & 42 \\
\hline
\end{tabular}

According to this study, the title social worker appears to be linked strongly to the concept of helping, with social workers being seen as helpful $(n=165)$. Closely aligned with helping, is the view that social work is also seen as meeting personal or community needs $(n=76)$. This view is consistent with some of the literature such as the Davidson and King (2005) study. Several people saw social work being linked to working with children and youth $(n=34)$ and statutory roles $(n=34)$. This is supported within the literature review where several studies reported a strong view that social work was associated with child protection. Twenty-two respondents also saw social workers being linked to counselling or someone who listens. This is consistent with Staniforth's 2010 study, which indicated that a majority of social workers reported undertaking counselling within their social work role.

Participants were asked to answer 'yes' or 'no' to indicate their awareness of roles of social workers. Table two shows the results to these questions. Respondents were most aware of the involvement social workers have in the area of 'child abuse and neglect', with 
95\% answering yes. The lowest level of awareness about the role of social workers was in the area of 'housing and welfare benefits', where only $74 \%$ were able to identify it as a role of a social worker.

Table two. Areas and roles of social work.

\begin{tabular}{lccc}
\hline Areas of social work & Yes & No & Could not respond \\
& & & 0 \\
Child abuse and neglect & $94.8 \%$ & $5.2 \%$ & 2 \\
Troubled teenagers? & $91.7 \%$ & $8.3 \%$ & 4 \\
Parents and parenting problems? & $90.1 \%$ & $9.9 \%$ & 7 \\
Mental illness and addictions? & $86.8 \%$ & $13.2 \%$ & 4 \\
Services for elders? & $80.9 \%$ & $19.1 \%$ & 7 \\
Health - adapting to illness? & $78.4 \%$ & $21.6 \%$ & 7 \\
Prison and probation? & $77.6 \%$ & $22.4 \%$ & \\
Roles of a social worker & & & \\
Support parents and families & $92.7 \%$ & $7.3 \%$ & 1 \\
Do counselling with people & $89.6 \%$ & $10.4 \%$ & 8 \\
Help people get resources & $88.6 \%$ & $11.4 \%$ & 14 \\
Help communities solve problems & $81 \%$ & $19 \%$ & 15 \\
Influence social policy & $65.1 \%$ & $34.9 \%$ & \\
Speak out against injustice & $62.5 \%$ & $37.5 \%$ & \\
& & & \\
\hline
\end{tabular}

People who had used social work services, or had had a family member use social work services believed slightly more strongly that social workers worked with parents and parenting problems $\left(\phi_{c}=.102, \mathrm{p}=.047\right)$ and in mental health and addictions $\left(\phi_{\mathrm{c}}=.113, \mathrm{p}=.027\right)$. This group also believed more strongly that social workers worked in the area of health and illness $\left(\phi_{\mathrm{c}}=.163, \mathrm{p}=.001\right)$, and slightly more strongly with elder services $\left(\phi_{\mathrm{c}}=.100, \mathrm{p}\right.$ $=.052$ ). There was a significant but weak association with women believing more strongly that social workers worked in the area of child abuse and neglect $\left(\phi_{c}=.114, p=.025\right)$ and with older (65+) and younger (18-24) participants less likely (weak association) to believe that social workers worked in the area of mental illness and addictions $\left(\phi_{c}=.195, \mathrm{p}=.013\right)$ or in the area of prison and probations $\left(\phi_{c}=.305, \mathrm{p}=.007\right)$. People aged 65 and over were less likely to believe that social workers worked with troubled teens $\left(\phi_{\mathrm{c}}=.199, \mathrm{p}=0.02\right)$, as were people living in Auckland $\left(\phi_{\mathrm{c}}=.164, \mathrm{p}=.036\right)$.

Respondents were asked to answer 'yes' or 'no' to indicate their knowledge of the contribution of professional social workers within the community. Table two continues to summarise these results, showing that $93 \%$ of participants thought that a role of professional social workers included supporting parents and families. The statement that had the least support was that professional social workers spoke out against injustice, with only $63 \%$ of respondents agreeing with this statement.

Men were less likely to believe that social workers helped get resources for people $\left(\phi_{\mathrm{c}}=\right.$ $.112, \mathrm{p}=.028$ ). People between the ages of 18 and 34 were more likely to believe that social workers spoke out against injustice, while those 45 and over were less likely to believe this $\left(\phi_{c}=.283 \mathrm{p}<.001\right)$. People between the ages of 18 to 34 were more likely to believe that social workers influenced social policy and those in the age range of 35 to 64 were less likely 
to agree with this, but with a weak association $\left(\phi_{\mathrm{c}}=.208, \mathrm{p}=.007\right)$.

In terms of areas of practice, results in this study tend to confirm findings from other studies (LeCroy \& Stinson, 2004) that the public perception of social work is heavily associated with working with children and youth, and most specifically with child abuse and neglect, with about $95 \%$ of respondents agreeing that this was an area of social work practice. The next two most 'agreed with' areas were working with troubled teenagers and parents and parenting. A majority did agree that social workers also worked in other areas.

In terms of the roles of social work, the most 'agreed with' role (which is consistent with areas of practice), is supporting parents and families, with around $93 \%$ of people agreeing with this as a social work role. Of note again, is the $90 \%$ agreement with the belief that social workers did counselling with people. While a majority of respondents did believe that social workers influenced social policy (65\%), and spoke out against injustice $(63 \%)$, they were the two lowest ranked items in terms of perception of roles. This is consistent with much of the social work literature which questions social work's commitment and ability to respond to the social change aspects of the profession within a global and neo-liberal political agenda (O'Brien, 2011a, 2011b, 2013; Hyslop, 2012). The view that social workers influenced social policy in this study is higher, however, than that found by LeCroy and Stinson (2004) where only $53.6 \%$ of their respondents believed this to be the case.

It is noted here that respondents were provided with a series of statements to respond to in relation to areas of social work practice, and roles of a social worker. These categories were constructed by the researchers. There is a likelihood that responses would have been different had the questions been more open-ended.

The international literature tended to emphasise the general lack of awareness around what social workers do in terms of their roles, both from within the profession, and by the public. Results of this study indicate that the public is generally well informed about the roles of social work (we help people), but support the research that states that the most frequently associated roles have to do with child protection and the least with social justice, policy and advocacy. This has implications in terms of the difficulties for social workers maintaining their commitment to social justice while being employed within agencies that emphasise the individual change and risk management functions within social work. A potential 'chicken and egg' situation arises where employers and funders of social workers and social work services may also hold this view and then further validate this perspective through only funding services that are in line with these roles.

\section{Working conditions}

Survey respondents were initially asked to rate their belief on a series of statements on a five-point scale. Table three lists each statement and the responses.

Table three reveals that $85.7 \%$ of the survey sample believed or strongly believed that social workers had a stressful job, with mean result of 4.3 out of five on Likert scale. Females were slightly more inclined to believe this than males, $\left(\phi_{c}=.181, \mathrm{p}=.027\right)$ and younger people (18-24) believed this slightly less than older age groups $\left(\phi_{\mathrm{c}}=.149 \mathrm{p}=.015\right)$. People who identified as European believed this slightly more, with a noteworthy but not significant difference, $\left(\phi_{\mathrm{c}}=.165, \mathrm{p}=.062\right)$ The majority of people $(71.5 \%)$ believed that social workers 
are hard working, with mean of 3.9/5, with European people believing this more strongly $\left(\phi_{\mathrm{c}}=.177, \mathrm{p}=.017\right)$ while just less than half $(49.8 \%)$ believed that the public trusted social workers (mean 3.4/5). Finally, only $23.7 \%$ of people believed that social workers were well paid (mean 2.8/5), with people in Christchurch and Wellington believing this less than people in Auckland, other North and other South Island $\left(\phi_{c}=.146, p=.036\right)$.

Table three. Working conditions and trust levels.

\begin{tabular}{lcccccc}
\hline Respondents (n) & Mean & $\begin{array}{c}\text { Strongly } \\
\text { disagree }\end{array}$ & Disagree & Neutral & $\begin{array}{c}\text { Strongly } \\
\text { agree }\end{array}$ & Agree \\
$\begin{array}{l}\text { In general, social workers in } \\
\quad \text { New Zealand have a } \\
\text { stressful job }\end{array}$ & 4.3 & $1.0 \%$ & $2.6 \%$ & $9.3 \%$ & $42.2 \%$ & $43.5 \%$ \\
$\begin{array}{l}\text { In general, social workers in } \\
\quad \text { New Zealand are }\end{array}$ & 3.9 & $0.0 \%$ & $5.7 \%$ & $16.4 \%$ & $55.1 \%$ & $16.1 \%$ \\
$\quad \begin{array}{l}\text { hard working } \\
\text { In general, New Zealanders } \\
\quad \text { trust social workers }\end{array}$ & 3.4 & $1.8 \%$ & $13.0 \%$ & $32.4 \%$ & $42.5 \%$ & $7.3 \%$ \\
$\begin{array}{l}\text { In general, social workers in } \\
\quad \text { New Zealand are well paid }\end{array}$ & 2.8 & $10.6 \%$ & $34.3 \%$ & $19.5 \%$ & $4.2 \%$ & $0.5 \%$ \\
\hline
\end{tabular}

Respondents in this study appeared to have a relatively sympathetic view regarding the working conditions of social workers, with the majority of respondents supporting the statements that 'social workers have a stressful job', that 'social workers are hard working', and that 'in general, New Zealanders trust social workers'. Responses to the trust question were divided however, with almost $15 \%$ of respondents having indicated that they did not believe that the public trusted social workers, and $32 \%$ being neutral on this question. There was a strong perception that social workers were not well paid, with only around 5\% of the respondents indicating a belief that social workers were well paid.

The perception of social work as a profession is likely to impact upon people's choice to enter social work education and choosing social work as a lifelong career, which in turn will affect recruitment and retention of social workers. Recruitment in Aotearoa New Zealand is an ongoing challenge, as in Aotearoa New Zealand, social work remains on the skills shortage for immigration purposes, meaning that there remains a need for social workers to fill vacancies. The social work population in New Zealand is also an aging one with approximately $74 \%$ of members being over the age of 40 and $45 \%$ being over 50 years of age (Geoff Pearman Partners in Change, 2011).

Results of this survey indicate that the public has a perception that social work is a stressful job, that social workers are hard working and not well paid. This is potentially concerning because if social work does not present itself as a particularly attractive career, then recruitment and retention issues will continue to pose a workforce problem.

With less than half of the participants indicating that they believed that the public trusted social workers, this is also likely to impact upon social workers remaining in the field and upon potential burnout. Feeling valued and trusted in one's job and in the work one does, is an important aspect of choosing to stay within it (LeCroy \& Stinson, 2004). 
Respondents were asked if they would encourage their children or a close family member to become a social worker. Of those responding to this question, $62.2 \%$ said that they would encourage their children or family members to become a social worker, while $37.8 \%$ of the respondents said that they would not. The only difference reported in this area that came close to being significant was that people aged 18 to 34 were more likely to encourage children or family to become social workers than those 35 and over $\left(\phi_{c}=.167, \mathrm{p}=0.061\right)$. Given the negative perception of working conditions reported by the respondents, the high number of responses to this question is somewhat surprising and bears further exploration.

\section{Registration and qualifications}

Survey respondents were asked to respond to the statement 'I believe that social workers are professionals and should be registered like doctors, nurses and teachers'. Of respondents, $83.3 \%$ stated 'yes', while $16.2 \%$ stated 'no'. Females in this study were slightly more inclined to report 'yes' to this statement $\left(\phi_{\mathrm{c}}=.150, \mathrm{p}=.003\right)$.

This is relatively consistent with the SWRB omnibus survey, conducted in 2012, where $81 \%$ of those surveyed believed that social workers were required by law to be registered and that their names were publically available on a register (SWRB 2012). Results from both this study and the SWRB study appear to confirm that the public believes that social workers should be registered and support calls from various sectors to the Government to move towards mandatory registration for social work.

Respondents were asked two questions in regards to educational requirements of social workers. The first question regarded what they believed the current basic level of education for social workers to be, and the second, what they believed it should be. Table four reveals the summary of results to both these questions.

Table four. Perceived and preferred requirements.

Level of education for social workers education level

None

School leaving (high school)

Diploma

Bachelor's degree

Higher degree (e.g. Masters or Ph.D.)
Perceived requirement

$12.4 \%$

$14.2 \%$

$34.5 \%$

$36.1 \%$

$2.7 \%$
Preferred requirement

$5.0 \%$

$13.4 \%$

$32.9 \%$

$42.9 \%$

$5.8 \%$

Females in the study indicated a moderately stronger belief that social workers should have degrees than males $\left(\phi_{c}=.298, p<.001\right)$. The members of the public surveyed for this study appeared well informed regarding the qualifications required for social work in Aotearoa New Zealand and they also appeared to believe that the requirements were what they 'should be'. Over $12 \%$ of people believed that no qualifications were required, while around $35 \%$ believed that a diploma was required, and 39\% believed that a Bachelor's degree or higher was required. About $49 \%$ of people in this study believed that a Bachelor's degree or higher should be what was required. These results appear consistent with those of the SWRB omnibus survey (SWRB, 2012). The SWRB study also found that $78 \%$ of the public believed that social workers needed to engage in continuing professional development in order to practice. 
While the majority of respondents in this study indicated that they believed a tertiary qualification was the expected and preferred qualification, they were not provided with an option that allowed them to indicate what length of time this qualification should take. This is a current issue that would have benefitted from some exploration given the recent signaling by the SWRB that the basic level of qualification being required is to become a four-year BSW or two-year professional Master's degree from 2017.

\section{Suggestions for improvement}

The second open-ended question asked survey participants to give their opinions about how social workers could improve the public perception of their profession. The most common response was that the profession should 'provide public information / be visible', with 77 of the 386 respondents (20\%) responding along these lines. The next most common response was 'demonstrate/validate effectiveness'.

Table five. Suggestions for improving image.

How to improve the public image of a social worker's profession Response

\section{Number of respondents}

$\begin{array}{ll}\text { Provide public information/be visible } & 77\end{array}$

$\begin{array}{lr}\text { Demonstrate/validate effectiveness } & 29\end{array}$

$\begin{array}{ll}\text { Advertise more } & 27\end{array}$

Need better training/qualifications $\quad 26$

$\begin{array}{ll}\text { Institute professional body } & 25\end{array}$

$\begin{array}{ll}\text { Be more open, confident, professional } & 19\end{array}$

Have to follow ideological/political line $\quad 18$

Be more available/approachable 14

$\begin{array}{ll}\text { Accountability for actions } & 12\end{array}$

Need more social workers/better resourcing $\quad 9$

$\begin{array}{ll}\text { Speak out about injustice } & 7\end{array}$

They don't need to do anything differently 4

Rename role from social worker to something without that stigma 2

$\begin{array}{ll}\text { Don't know/none } & 102\end{array}$

Other 49

This research has provided some new data and suggestions regarding how the public believes that the image of social workers and the profession of social work could be improved. With the most frequent response being that social work should provide more public information and become more visible, this appears to be something that is within the profession's grasp. Perhaps more troubling is the view that social workers needed to be better at what they do and to demonstrate their effectiveness. This view may also possibly be aligned with negative portrayals of the profession in the media, where highly emotive stories, often associated with violence and incompetence, are frequently presented. Further study in this area is warranted.

\section{Conclusion}

This article has attempted to present recent data from a study that explored the public perception of social work in Aotearoa New Zealand. The 'public' in this case appears to be relatively informed about what social workers do and what qualifications they are required 
to have to do it. A majority of respondents indicated that they would encourage their children or a close family member to become a social worker. This, despite the fact that they were also aware of the high stress associated with the job, the low pay and the hard work that is required, as well as some uncertainty about what it actually is that social workers do.

These results demonstrate a level of public confidence, but not to such a degree that there should be complacence. This study has presented a baseline only. There is still much to do in terms of role clarification and as a profession, there is a need to have ongoing debates about both how social workers themselves view the role of social work in Aotearoa New Zealand, and also how this is communicated to stakeholders within social work and the public. This has implications for social work education, professional associations and employers of social workers. Similarly, there is much to do about the perceived satisfaction within the profession, in that it is widely recognised as a stressful job, but the perceived benefits might be less well known. A study that explores why social workers stay in their jobs and what they like about their work would have the potential to present a more balanced view and encourage others into the profession. These studies are needed in order to inform the development of the profession so it is well placed to meet the ongoing need for social workers and to improve the conditions for those working in social work, and ultimately those they serve.

The belief that social workers should be registered has been endorsed in both this study and the SWRB 2011 study. This, considered alongside the perception that most social workers should have an advanced qualification is another core message for the profession, its funders and its regulators to hear.

Acknowledgements. The authors would like to acknowledge Natasha Urale Baker for her work on the literature review.

\section{References}

Beddoe, L. (2003). Danger and disdain: Truth or dare in social work education. Women in Welfare Education (Australia), 6 (Special Field Education Edition), 13-25. Retrieved from http:/ / www.aaswwe.asn.au/wiwe/default.htm.

Black, K. (2006). Advance directive communication: Nurses' and social workers' perceptions of roles. American Journal of Hospice and Palliative Medicine, 23(3) 175-184.

Briggs, C., Meagher, G., \& Healy, K. (2007). Becoming an industry: The struggle of social and community workers for award coverage, 1976-2001. Journal of Industrial Relations, 49(4), 497-521.

Brodie, I., Nottingham, C., \& Plunkett, S. (2008). A tale of two reports: Social work in Scotland from Social work and the community (1966) to Changing lives (2006). British Journal of Social Work, 38(4), 697-715.

Brown, M. (2000). Care and protection is about adult behaviour: The Ministerial Review of the Department of Child, Youth and Family Services. Retrieved from https: / / www.msd.govt.nz/documents/about-msd-and-our-work/publications-resources / archive / 2000-care-and-protection-is-about-adult-behaviour.pdf.

Census New Zealand. (2013). Census New Zealand statistics 2013. http:/ / www.stats.govt.nz/Census / 2013-census. aspx.

Condie, C. D., Hanson, J. A., Lang, N. E., Moss, D. K., \& Kane, R. A. (1978). How the public views social work. Social Work, 23(1), 47-53.

Davidson, S., \& King, S. (2005). Public knowledge of and attitudes to social work in Scotland. Edinburgh, Scotland: Scottish Executive Social Research.

Dennison, S. T., Poole, J., \& Qaquish, B. (2007). Student's perceptions of social work: Implications for strengthening the image of social work among college students. Social Work, 52(4), 350-360.

Egan, M., \& Kadushin, G. (1995). Competitive allies: Rural nurses' and social workers' perceptions of the social work role in the hospital setting. Social Work in Health Care, 20(3), 1-23.

Freeman, M. L., \& Valentine, D. P. (2004). Through the eyes of Hollywood: Images of social workers in film. Social Work, 49(2), 151-161.

Gaughan, L., \& Garrett, P. M. (2011). The 'most twisted and unaccountable force in the state'? Newspaper accounts of social work in the Republic of Ireland in troubled times. Journal of Social Work, 12(3), 267-286. 
Geoff Pearman Partners in Change. (2011). Scoping report 'The Learning Exchange'. Aotearoa New Zealand Association of Social Workers. Auckland, New Zealand: Author.

Gerritsen-McKane, R., Hunter, R., \& Ofori-Dua, K. (2013). Professional perceptions of social work and potential impact on developing field. Qualitative Social Work, 12(6) 816-832.

Hackett, S., Kuronen, M., Matthies, A., \& Kresal, B. (2003). The motivation, professional development and identity of social work students in four European countries. European Journal of Social Work, 6(2), 163-178.

Henderson, L., \& Franklin, B. (2007). Sad not bad. Images of social care professionals in popular UK television drama. Journal of Social Work, 7(2), 133-153.

Hyslop, I. (2012). Social work as a practice of freedom. Journal of Social Work, 12(4), 404-422.

Jones, C. A., Vela, E., Vang, T., \& Walde, B. D. (2006). Perceptions of social work: Undergraduate students assess the profession. The Journal of Baccalaureate Social Work, 12(1), 1-12.

Keefe, B., Geron, S. M., \& Enguidanos, S. (2009). Integrating social workers into primary care: Physician and nurse perceptions of roles, benefits, and challenges. Social Work in Health Care, 48(6), 579-596.

Krumer-Nevo, M., \& Weiss, I. (2006). Factors affecting the interest of Israeli social work students in working with different client groups. Journal of Social Work Education, 42(3), 443-446.

LeCroy, C. W., \& Stinson, E. L. (2004). The public's perception of social work: Is it what we think it is? Social Work, 49(2), 164-174.

Lytollis, S. (1996). Making the best of the media spotlight. Social Work Now (5), 15-20.

McPhail, B. A. (2004). Setting the record straight: Social work is not a female-dominated profession. Social Work, 49(2), 323-326.

National Association of Social Workers (2003). Social work profession: A call to action. Paper presented at the 2 nd SocialWork Summit, Washington, D.C. Retrieved from http: / / www.naswdc.org/nasw/NASW-SummitWeb2003.pdf

Netting, F., \& Williams, F. (1996). Case manager-physician collaboration: Implications for professional identity, roles, and relationships. Health E Social Work, 21(3), 216-224.

O'Brien, M. (2011a). Equality and fairness: Linking social justice and social work practice. Journal of Social Work, 11(2), 143-158.

O’Brien, M. (2011b). Social justice: Alive and well (partly) in social work practice? International Social Work, 54(2), 174-190.

O'Brien, M. (2013). Social work registration and professionalism: Social justice and poverty - fellow travellers or discarded passengers? Aotearoa New Zealand Social Work, 25(3), 50-59.

Pease, B. (2011). Men in social work. Affilia, 26(4), 406-418.

Postle, K. (2001). The social work side is disappearing. I guess it started with us being called care managers. Practice, 13(1), pp. 13-26.

Schmid, H. \& Benbenishty, R. (2011). Public attitudes toward child maltreatment in Israel: Implications for policy. Children and Youth Services Review, 33(7), 1181-1188.

Social Workers Registration Board. (2011). Omnibus survey. Unpublished.

Social Workers Registration Board. (2012). Social Workers Registration Act (2003). Review report, October 2012. Wellington, New Zealand: Author.

Stanfield, D., \& Beddoe, L. (2013). Social work and the media: A collaborative challenge. Aotearoa New Zealand Social Work, 25(4), 41-51.

Staniforth, B. (2010). Past present and future perspectives on the role of counselling in social work in Aotearoa New Zealand. PhD Thesis, Massey University, New Zealand.

Staniforth, B., Fouché, C. \& O'Brien, M. (2011). Still doing what we do: Defining social work in the 21st century. Journal of Social Work, 11(2), 191-208

Statistics New Zealand (2014). 2013 Census. Retrieved from http: / / www.stats.govt.nz/Census / 2013-census.aspx.

Turner, M. J. (2011) 'How do I look?' A research report on people's perceptions about social workers. Unpublished master's report, Massey University, Auckland, New Zealand.

van Heugten, K. (2011). Social work under pressure: How to overcome stress, fatigue and burnout in the workplace. London, England: Jessica Kingsley Publishers.

Zugazaga, C. B., Surette, R. B., Mendez, M., \& Otto, C. W. (2006). Social worker perceptions of the portrayal of the profession in the news and entertainment media: An exploratory study. Journal of Social Work Education, 42(3), 621-636. 